\title{
Serum SDF-1 levels are a reliable diagnostic marker of feline mammary carcinoma, discriminating HER2-overexpressing tumors from other subtypes
}

\author{
Cláudia S. Marques ${ }^{1}$, Maria Soares ${ }^{1}$, Ana Santos $^{1}$, Jorge Correia $^{1}$ and Fernando \\ Ferreira $^{1}$ \\ ${ }^{1}$ Center for Interdisciplinary Research in Animal Health, Faculty of Veterinary Medicine, University of Lisbon, 1300-477 \\ Lisbon, Portugal \\ Correspondence to: Fernando Ferreira, email: fernandof@fmv.ulisboa.pt \\ Keywords: feline mammary carcinoma; SDF-1; serum biomarker; HER2; CXCR4 \\ Received: September 07, $2017 \quad$ Accepted: October 25, $2017 \quad$ Published: November 11, 2017 \\ Copyright: Marques et al. This is an open-access article distributed under the terms of the Creative Commons Attribution License \\ 3.0 (CC BY 3.0), which permits unrestricted use, distribution, and reproduction in any medium, provided the original author and \\ source are credited.
}

\section{ABSTRACT}

The feline mammary carcinoma (FMC) is the third most common tumor in cat, sharing many clinicopathological features with human breast cancer and thus, considered a suitable model for comparative oncology. Due to its poor prognosis, further studies are required to improve the diagnostic accuracy and treatment of cats with spontaneous mammary carcinoma. Recently, it was reported that the overexpression of stromal cell-derived factor-1 (SDF-1) has great value in human breast cancer diagnosis, suggesting that diagnostic tools and therapies targeting the SDF-1 ligand can improve the clinical outcome. In this study, we aimed to evaluate if serum SDF-1 levels can also be used as a biomarker of mammary carcinoma in cats and to analyze if serum SDF-1 levels are associated with clinicopathological features, linked to a specific FMC subtype or correlated with the tumor expression of SDF-1 receptor, the chemokine C-X-C motif receptor 4 (CXCR4). Results showed that cats with mammary carcinoma had significantly higher serum SDF-1 levels than healthy controls $(p=0.035)$ and ROC analysis revealed that the best cut-off value to differentiate sick from healthy animals was $2 \mathrm{ng} / \mathrm{ml}$ (specificity: 80\%; sensitivity: $57 \%$; AUC=0.715). Significant associations were also found between cats with elevated serum SDF-1 concentrations $(\geq 2 \mathrm{ng} / \mathrm{ml})$ and HER2-overexpressing mammary carcinomas (Luminal B-like and HER2-positive subtypes, $p<0.0001$ ), CXCR4-negative mammary carcinomas $(p=0.027)$, mammary carcinomas with small size $(<3 \mathrm{~cm}, p=0.027)$ and tumors with low Ki-67 expression $(p=0.012)$. No statistical associations were found between serum SDF-1 levels and overall or disease-free survival. In summary, our results show that serum SDF-1 levels can be used as a biomarker of feline mammary carcinoma, especially in cats with HER2-overexpressing mammary tumors. Data suggest that targeted therapies against the SDF-1 ligand and/or its CXC4 receptor may be effective for the treatment of FMC, as described for human breast cancer, strengthening the concept that spontaneous feline mammary carcinoma is a suitable model for comparative oncology. 


\section{INTRODUCTION}

The feline mammary carcinoma (FMC) is very common in cat (12-40\% of all neoplasms), showing overexpression of the HER2 protooncogene in 33\%-60\% of the cases [1-5]. Sharing phenotypic and genotypic similarities with human breast tumor [6-10], spontaneous FMCs can also be classified in the same subtypes (luminal A, luminal B, luminal B-like, epidermal growth factor receptor type II-positive and triple negative) [7, 11], being considered a suitable model for breast cancer studies.

Despite the efforts to understand the oncogenic mechanisms of breast cancer, the discovery of more accurate biomarkers and therapeutic targets are listed as research priorities [12]. Considering this scenario, an increasing attention is given to a family of chemotactic molecules known as chemokines, which are secreted by a variety of stromal and epithelial cells, exerting its biological effects by interacting with $\mathrm{G}$ protein-coupled receptors (GPCR). Their binding to these receptors mediates leukocyte migration and adhesion to the tumor endothelial cells, regulating the tumor growth, angiogenesis and apoptosis [13,14]. Indeed, recent studies showed that the binding of stromal cell-derived-factor-1 (SDF-1), also known as chemokine ligand 12 (CXCL12), to the $\mathrm{C}-\mathrm{X}-\mathrm{C}$ chemokine receptor 4 (CXCR4) increases the proliferation rates and stromal vascular endothelial growth of several types of cancer [15-17], including breast tumors [18-23]. Moreover, since the SDF-1/CXCR4 axis elicits the activation of multiple kinase pathways (e.g. PI3K, MAPK, ERK1/2), its inhibition may represent a new therapeutic strategy to treat mammary tumors more effectively. Besides, the CXCR4 overexpression has been observed in metastatic breast cancer patients [24-28], especially in HER2-overexpressing [29-33] and triple negative breast tumors [34-39], suggesting that SDF-1 receptor inhibition might constitute a novel therapeutic approach. Regarding the expression of the SDF-1, little is known. Nevertheless, some studies reported that breast cancer patients display increased serum SDF-1 levels, in particular patients with HER2-overexpressing breast tumors [40] and that serum SDF-1 concentration has prognostic value [19, 40-44].

In cat, only scarce data is available on the molecular mechanisms underlying the SDF-1/CXCR4 axis. In 2002, Tanabe at al. [45] showed that CXCR4 is overexpressed in $72 \%$ cases of feline mammary adenocarcinomas and 10 years later, Ferrari and et al. [46] demonstrated that SDF$1 /$ CXCR4 axis has a proliferative role in feline mammary carcinoma cells. Taking into account the oncogenic role of the SDF-1/CXCR4 axis in human breast cancer and the promising data on its inhibition, we aimed to determine if the serum SDF-1 levels have diagnostic value in cats with mammary carcinoma and to calculate the best cutoff value, which allows to discriminate between sick and healthy animals. Finally, the statistical associations between serum SDF-1 levels and different FMC subtypes, tumor's CXCR4 expression and clinicopathological features were estimated, in order to better understand the clinical relevance of the SDF-1 ligand in cat, towards the development of diagnostic tools and targeted therapies.

\section{RESULTS}

\section{Animal study population}

The main clinicopathological features of the cats with mammary carcinoma enrolled in the study $(n=42)$, are summarized in Table 1. The mean age at diagnosis was $11.51 \pm 2.62$ years ranging from 7 to 16.5 years. All animals were submitted to surgical mastectomy and four $(10 \%)$ were subjected to anthracycline-based adjuvant chemotherapy (doxorubicin, $25 \mathrm{mg} / \mathrm{m} 2$, intravenously, every 3 weeks for 5 cycles). Eleven queens (26\%) showed HER2-overexpressing mammary carcinomas, whereas fourteen cats $(33 \%)$ had elevated serum HER2 levels (Table 1). The overall survival (OS) was $16.39 \pm 10.16$ months $(\mathrm{n}=41)$ and the survival ratio was $50 \%$. The disease free-survival (DFS) was $12.15 \pm 7.84$ months $(n=34)$ and nineteen $(56 \%)$ of the cats with mammary carcinoma had disease recurrence at the end of the follow-up period (54 months), with $50 \%$ of the cats showing locoregional recurrence $(\mathrm{n}=17)$ and $6 \%$ displaying distant metastases $(n=2)$.

\section{Cats with mammary carcinoma showed higher serum SDF-1 levels than healthy cats}

Knowing that human SDF-1 and feline SDF-1 share $96 \%$ amino acid identity, serum SDF-1 levels were measured using a commercial ELISA kit and following the manufacturer's recommendations. Serum SDF-1 concentrations were then calculated from the standard curve generated by serial dilutions of recombinant SDF-1 protein with known concentrations (Figure $1, \mathrm{R}^{2}=0.99$ ). Results revealed that cats with mammary carcinoma exhibited higher serum SDF-1 levels (mean value of 8.76 $\mathrm{ng} / \mathrm{ml}$; range of values: $0.45-36.72 \mathrm{ng} / \mathrm{ml}$ ) than healthy cats (mean $=1.28 \mathrm{ng} / \mathrm{ml}$; range of values: $0.38-2.69) \mathrm{ng} /$ $\mathrm{ml}$ ), with a significant $p$-value of 0.035 (Figure 2).

\section{Serum SDF-1 levels $\geq 2 \mathrm{ng} / \mathrm{ml}$ give the best cut-off value to diagnose cats with mammary carcinoma}

Receiver-operating characteristics (ROC) analysis was performed to determine the best cut-off point for serum SDF-1 levels, using ELISA as a diagnostic tool. ROC analysis revealed that $2 \mathrm{ng} / \mathrm{ml}$ is the best cut-off value to discriminate cats with mammary carcinoma from healthy ones (Figure 3), with a specificity of $80 \%$, a sensitivity of $57 \%$ and an area under the curve 
Table 1: Clinicopathological features of the cats with mammary carcinoma enrolled in the study

\begin{tabular}{|c|c|c|c|}
\hline Clinicopathological feature & No. of animals (\%) & Clinicopathological feature & No. of animals (\%) \\
\hline Breed & & Tumor Size & \\
\hline Not determined & $30(71 \%)$ & $\leq 3 \mathrm{~cm}$ & $31(74 \%)$ \\
\hline Siamese & $7(17 \%)$ & $>3 \mathrm{~cm}$ & $11(26 \%)$ \\
\hline Persian & $3(7 \%)$ & HPa classification & \\
\hline Norwegian Forest Cat & $2(5 \%)$ & Papillary-cystic carcinoma & $2(5 \%)$ \\
\hline Spayed & & Cribriform carcinoma & $3(7 \%)$ \\
\hline No & $25(60 \%)$ & Mucinous carcinoma & $5(12 \%)$ \\
\hline Yes & $16(38 \%)$ & Solid carcinoma & $7(16 \%)$ \\
\hline Unknown & $1(2 \%)$ & Tubular carcinoma & $10(24 \%)$ \\
\hline Contraceptives & & Tubulopapillary carcinoma & $15(36 \%)$ \\
\hline No & $13(31 \%)$ & Malignancy grade & \\
\hline Yes & $21(50 \%)$ & I & $2(5 \%)$ \\
\hline Unknown & $8(19 \%)$ & II & $10(24 \%)$ \\
\hline Treatment & & III & $30(71 \%)$ \\
\hline Mastectomy & $38(90 \%)$ & Necrosis & \\
\hline Mastectomy + Chemo & $4(10 \%)$ & No & $17(40 \%)$ \\
\hline Multiple tumors & & Yes & $25(60 \%)$ \\
\hline No & $12(29 \%)$ & Lymphatic invasion & \\
\hline Yes & $30(71 \%)$ & No & $35(83 \%)$ \\
\hline Lymph node status & & Yes & $7(17 \%)$ \\
\hline Negative & $23(55 \%)$ & Lymphocytic infiltration & \\
\hline Positive & $14(33 \%)$ & No & $20(48 \%)$ \\
\hline Unknown & $5(12 \%)$ & Yes & $22(52 \%)$ \\
\hline Tumor stage (TNM) & & Tumor ulceration & \\
\hline I & $11(26 \%)$ & No & $40(95 \%)$ \\
\hline II & $7(17 \%)$ & Yes & $2(5 \%)$ \\
\hline III & $22(52 \%)$ & Ki 67 index & \\
\hline IV & $2(5 \%)$ & Low $(<14 \%)$ & $15(36 \%)$ \\
\hline Localization & & High $(\geq 14 \%)$ & $26(62 \%)$ \\
\hline M1 & $9(22 \%)$ & Unknown & $1(2 \%)$ \\
\hline M2 & $9(22 \%)$ & PR status & \\
\hline M3 & $17(40 \%)$ & Negative & $22(52 \%)$ \\
\hline M4 & $6(14 \%)$ & Positive & $20(48 \%)$ \\
\hline Unknown & $1(2 \%)$ & ER status & \\
\hline Recurrence & & Negative & $25(60 \%)$ \\
\hline No & $14(33 \%)$ & Positive & $17(40 \%)$ \\
\hline Yes & $20(48 \%)$ & HER2 status & \\
\hline
\end{tabular}

(Continued) 


\begin{tabular}{lclc}
\hline Clinicopathological feature & No. of animals (\%) & Clinicopathological feature & No. of animals (\%) \\
\hline Unknown & $8(19 \%)$ & Negative & $31(74 \%)$ \\
Survival (42 months follow-up) & & Positive & $11(26 \%)$ \\
No & $21(50 \%)$ & Serum HER2 levels & \\
Yes & $20(48 \%)$ & Negative $(<10 \mathrm{ng} / \mathrm{ml})$ & $21(50 \%)$ \\
Unknown & $1(2 \%)$ & Positive $(\geq 10 \mathrm{ng} / \mathrm{ml})$ & $14(33 \%)$ \\
& & Unknown & $7(17 \%)$ \\
\hline
\end{tabular}

${ }^{a}$ Histopathological.

(AUC) of 0.715 (95\% CI: 0.566-0.865, SEM=0.076). To reinforce the utility of measuring serum SDF-1 levels in cats with mammary carcinoma, a nonparametric method that does not make any assumptions about the distribution of ELISA results in both groups was used and a significant $p$-value was obtained $(p=0.036)$. Indeed, only two of the ten healthy cats $(20 \%)$ showed serum SDF-1 levels $\geq 2 \mathrm{ng} / \mathrm{ml}$, whereas the majority of cats with mammary carcinoma exhibited elevated serum SDF-1 levels (Table 2).

\section{Elevated serum SDF-1 levels are associated with HER2-overexpressing feline mammary carcinomas}

Cats enrolled in this study were grouped in four clusters based on their tumor subtype, in order to determine if serum SDF-1 levels are correlated with a specify mammary carcinoma immunophenotype. Cats with HER2-overexpressing mammary carcinomas (Luminal B-like and HER2-positive subtypes) showed higher serum SDF-1 levels $(16.07 \pm 9.26 \mathrm{ng} / \mathrm{ml})$ than cats with mammary carcinoma from other subtypes $(p<0.001$, Figure 4$)$. Further ROC analysis revealed that $4 \mathrm{ng} / \mathrm{ml}$ is the best cut-off value to differentiate cats with HER2-overexpressing phenotype and cats presenting other molecular subtypes (Figure 5), with a specificity of $96 \%$, a sensitivity of $100 \%$ and a significant area under the curve (AUC) of 0.972 (95\% CI: 0.917-1.027, $\mathrm{SEM}=0.028, p<0.0001)$. In addition, a positive correlation was found between serum SDF-1 levels and serum HER2 levels ( $r=0.69,95 \%$ CI: $0.46-0.84, p<0.0001$, Figure 6), corroborating the previous results, since the serum HER2 levels are associated with tumor HER2 status [11].

\section{Cats with CXCR4-overexpresing mammary carcinomas showed low serum SDF-1 levels}

The CXCR4 expression was evaluated by using a semi-quantitative scoring system previously published $[19,21,26,46]$. Briefly, the staining intensity (weak, moderate, strong) and the number of labeled tumor cells were analyzed (Figure 7A), with the CXCR4-negative tumor samples being scored as 0 (Figure 7A, c) or 1+ (Figure 7A, d), and CXCR4-positive tumor samples classified as 2+ (Figure 7A, e) or 3+ (Figure 7A, f). From the 42 feline mammary carcinomas evaluated, $6(14 \%)$ samples were classified as CXCR4-negative samples and $36(86 \%)$ as CXCR4-positive samples, with CXCR4negative mammary carcinoma showing significant higher serum SDF-1 levels ( $p=0.027$, Figure 7B).

\section{Cats with elevated serum SDF-1 levels showed less aggressive clinicopathological features}

Significant associations were found between cats with elevated serum SDF-1 levels $(\geq 2 \mathrm{ng} / \mathrm{ml})$ smaller mammary carcinomas $(\leq 3 \mathrm{~cm} ; p=0.012 ; \mathrm{OR}=0.068$; 95\% CI: $0.007-0.63$ ) and tumors with lower Ki-67 index $(<14 \%, p=0.037 ;$ OR $=0.185 ; 95 \%$ CI: 0.04-0.84) (Table 3 ). In addition, cats with elevated serum SDF-1 levels ( $\geq 2$ $\mathrm{ng} / \mathrm{ml}$ ) were associated with cats showing HER2-positive mammary carcinomas $(p=0.0001$; OR $=53.67 ; 95 \% \mathrm{CI}$ : 2.78 - 1034). Finally, no significant differences in overall and disease-free survival rates were found between cats with mammary carcinoma showing increased serum SDF1 levels and cats with mammary carcinomas exhibiting decreased serum SDF-1 levels.

\section{DISCUSSION}

Due to the similarities between human breast cancer and feline mammary carcinoma [6-10], new clinical studies on FMC may identify novel diagnostic markers and therapeutic targets that can probably be used in human patients. Recently, it was demonstrated that stroma cells of breast tumors synthesize the chemokine SDF-1, which via its cognate receptor (CXCR4) supports tumor growth through autocrine and paracrine mechanisms $[14,19,24$, $41,47]$. Moreover, it was showed that breast cancer cells overexpressing CXCR4 metastasize to distant sites, where SDF-1 is highly expressed $[18,48]$, raising the possibility that targeted therapies against SDF-1/CXCR4 axis may inhibit tumor growth, as described in vitro [49-54]. However, despite these promising findings, the value of serum SDF-1 levels in the diagnosis and their correlation 


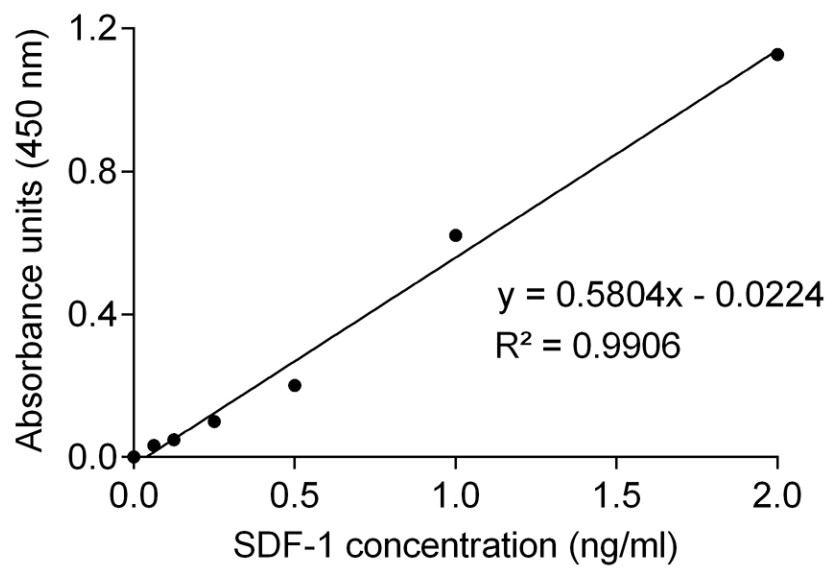

Figure 1: Standard curve for quantification of serum SDF-1 levels by ELISA. Concentrations of SDF-1 were calculated by replacing the $\mathrm{X}$ in the trend line equation by the average of the absorbance units measured in duplicate for each sample. $\mathrm{R}$-square $\left(\mathrm{R}^{2}\right)$ value of the linear regression was higher than 0.99 .

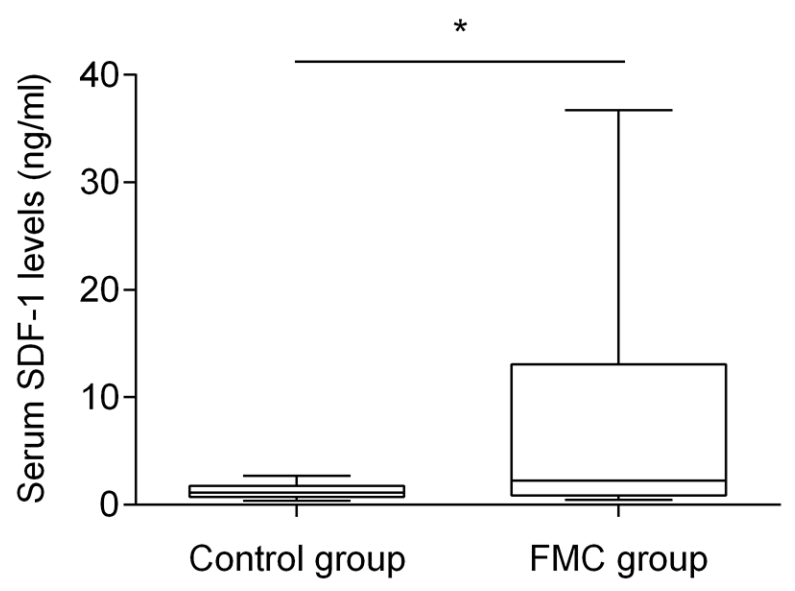

Figure 2: Box plot diagrams showing that queens with mammary carcinoma (FMC group) have higher serum SDF1 levels than healthy cats (control group). The non-parametric Mann-Whitney U test was used to compare serum SDF-1 levels between the two groups. ${ }^{*}$ indicates significant difference $(p=0.035)$.

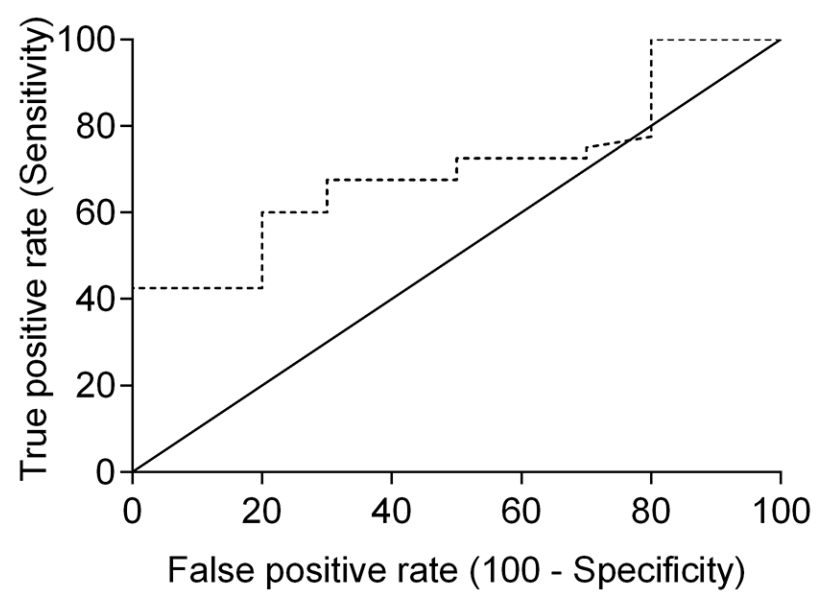

Figure 3: Receiver-operating characteristic (ROC) curve of serum SDF-1 levels for ELISA. The best SDF-1 cut-off value (2 $\mathrm{ng} / \mathrm{ml}$ ) was determined to maximize the sum of the sensitivity $(57 \%)$ and specificity $(80 \%)$ using the Youden index (sensitivity + specificity - 1). The estimated AUC was $0.715 \pm 0.076$ (95\% CI: 0.566-0.865, $p=0.036)$. 
Table 2: Serum SDF-1 levels in healthy cats and in cats with mammary carcinoma, measured by ELISA

\begin{tabular}{lcc}
\hline & Animals (\%) & Mean and range values (ng/ml) \\
\hline Healthy cats $(\mathbf{n}=\mathbf{1 0})$ & & $0.93(0.38-1.44)$ \\
Low levels $(<2 \mathrm{ng} / \mathrm{ml})$ & $2(80 \%)$ & $2.69(2.58-2.80)$ \\
High levels $(\geq 2 \mathrm{ng} / \mathrm{ml})$ & $2(20 \%)$ & $0.84(0.45-1.60)$ \\
Sick cats $(\mathbf{n}=\mathbf{4 2})$ & $17(40 \%)$ & $14.14(2.00-36.72)$ \\
Low levels $(<2 \mathrm{ng} / \mathrm{ml})$ & $25(60 \%)$ & \\
High levels $(\geq 2 \mathrm{ng} / \mathrm{ml})$ & & \\
\hline
\end{tabular}

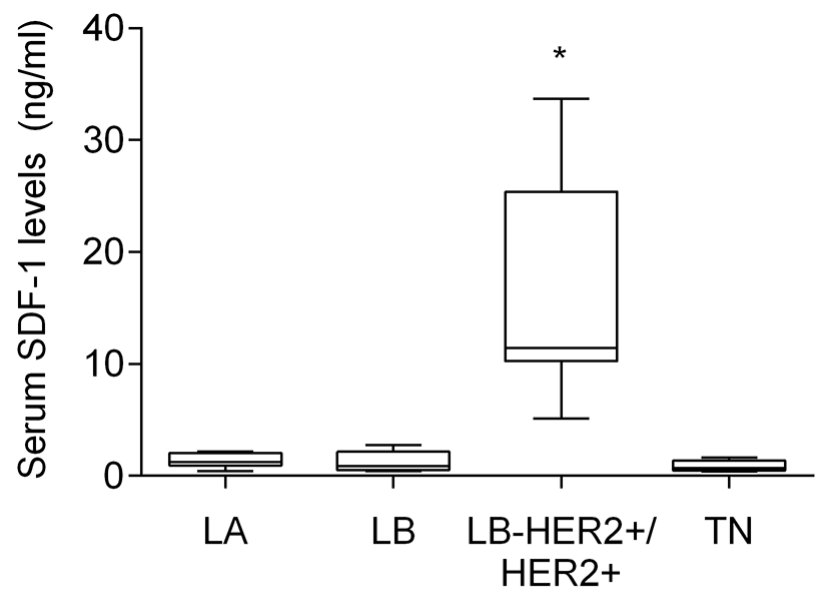

Tumor subtypes

Figure 4: Cats with HER2-overexpressing mammary carcinoma show higher serum SDF-1 levels. Mammary carcinomas were classified accordingly to the St. Gallen International Expert Consensus panel guidelines. To compare circulating SDF-1 levels between animals with different FMC subtypes ( $L A$ - luminal A; $L B$ - luminal B; $L B$-HER2+/HER2+ - luminal B-like/HER2-positive; TNnormal and basal triple-negative), the non-parametric Kruskall-Wallis test and Dunn's multiple comparisons post-test were used. ${ }^{*}$ indicates significant differences between cats with HER2-overexpressing mammary carcinomas $(L B-H E R 2+/ H E R 2+)$ and cats with other FMC subtypes $(p<0.05)$.

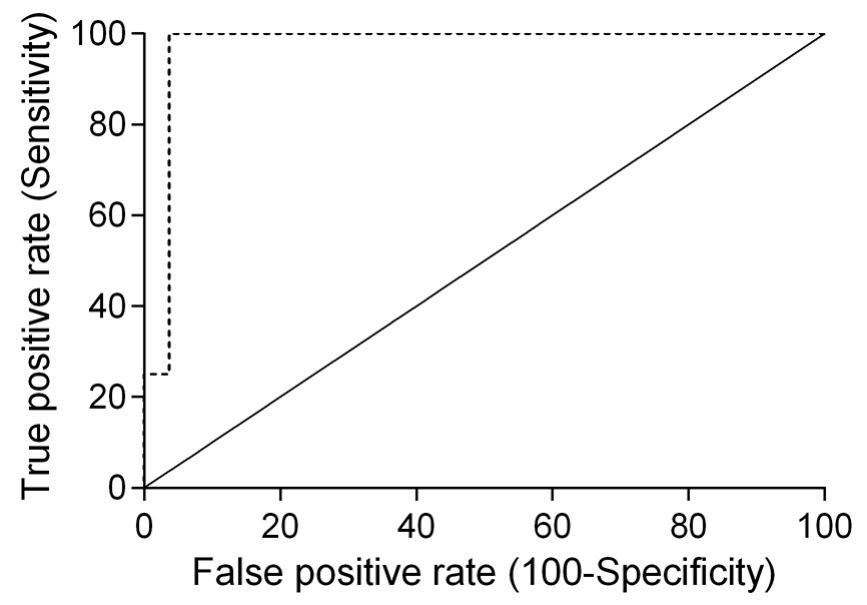

Figure 5: Receiver-operating characteristic (ROC) curve of serum SDF-1 levels of cats with HER-2-overexpressing and HER-2 negative tumors. The best cut-off value $(4 \mathrm{ng} / \mathrm{ml})$ was determined to maximize the sum of the sensitivity (100\%) and specificity (96\%) using the Youden index (sensitivity + specificity - 1). The estimated AUC was $0.972 \pm 0.028$ (95\% CI: 0.917-1.027, $p<0.0001)$. 
with clinicopathological features are unknown in cats and poorly understood in humans.

In the present study, we demonstrated that serum SDF-1 levels have diagnostic value in cats with mammary carcinoma and determined that the best cut-off value to discriminate cats with mammary carcinoma from healthy ones $(\geq 2 \mathrm{ng} / \mathrm{ml})$ is close to the one reported for breast cancer patients $[40,43]$, reinforcing the idea that FMC is a suitable cancer model. Furthermore, a significant association was found between cats with HER2-overexpressing mammary carcinomas (luminal B-like and HER2+ subtypes) and cats with high serum SDF-1 levels, as reported for breast cancer patients [40, 43]. Indeed, cats with elevated serum SDF-1 levels have 53 times more likelihood to show HER2-positive tumor status and increased serum HER2 values $(p<0.0001)$, corroborating the recent data that associates the HER2 tumor status with the serum HER2 levels [11], as also reported in humans $[55,56]$. Further ROC analysis also revealed a cut-off value of $4 \mathrm{ng} / \mathrm{ml}$ in serum levels, that allows differentiation of HER-2 positive from HER-2 negative tumor samples. Considering the proliferative role of SDF-1/CXCR4 axis in breast tumors $[27,28]$ and the promising in vitro results obtained with CXCR4 inhibitors, the expression of the SDF-1 receptor was also evaluated in feline mammary carcinomas. The immunohistochemical analysis revealed that $\mathrm{CXCR} 4$ is overexpressed in the majority of FMC $(36 / 42 ; 86 \%)$, as previously reported in cat [46] and in breast cancer patients [27, 28]. In addition, cats with CXCR4-positive mammary carcinomas showed lower serum SDF-1 levels then cats with CXCR4-negative mammary carcinomas $(p=0.027)$, uncovering a putative negative feedback of the SDF-1 ligand on SDF-1/CXCR4 axis. In breast cancer patients it was reported that low serum SDF-1 levels may favor the migration of tumor cells overexpressing CXCR4, promoting the development of distant metastasis [19]. Interestingly, we found that cats with elevated serum SDF-1 levels are associated with mammary carcinomas showing smaller size $(\leq 3$ $\mathrm{cm} ; p=0.012)$, lower ki-67 index $(<14 \% ; p=0.037)$ and HER2 overexpression ( $p=0.0001)$, with 9 from 11 HER2overexpressing mammary carcinomas $(81.8 \%)$, being classified as luminal B-like subtype, which is associated with a better outcome than HER2 subtype, both in cat [7] and humans [57-60].

So far, few attempts were made to correlate the expression levels of the SDF-1 receptor, CXCR4 and the different molecular subtypes in human breast cancer. Nevertheless, an elegant study established a functional link between the HER2 and CXCR4 signaling pathways, being the PI3K/Akt/mTOR pathway activation responsible for the HER2-induced CXCR4 expression and the HER2

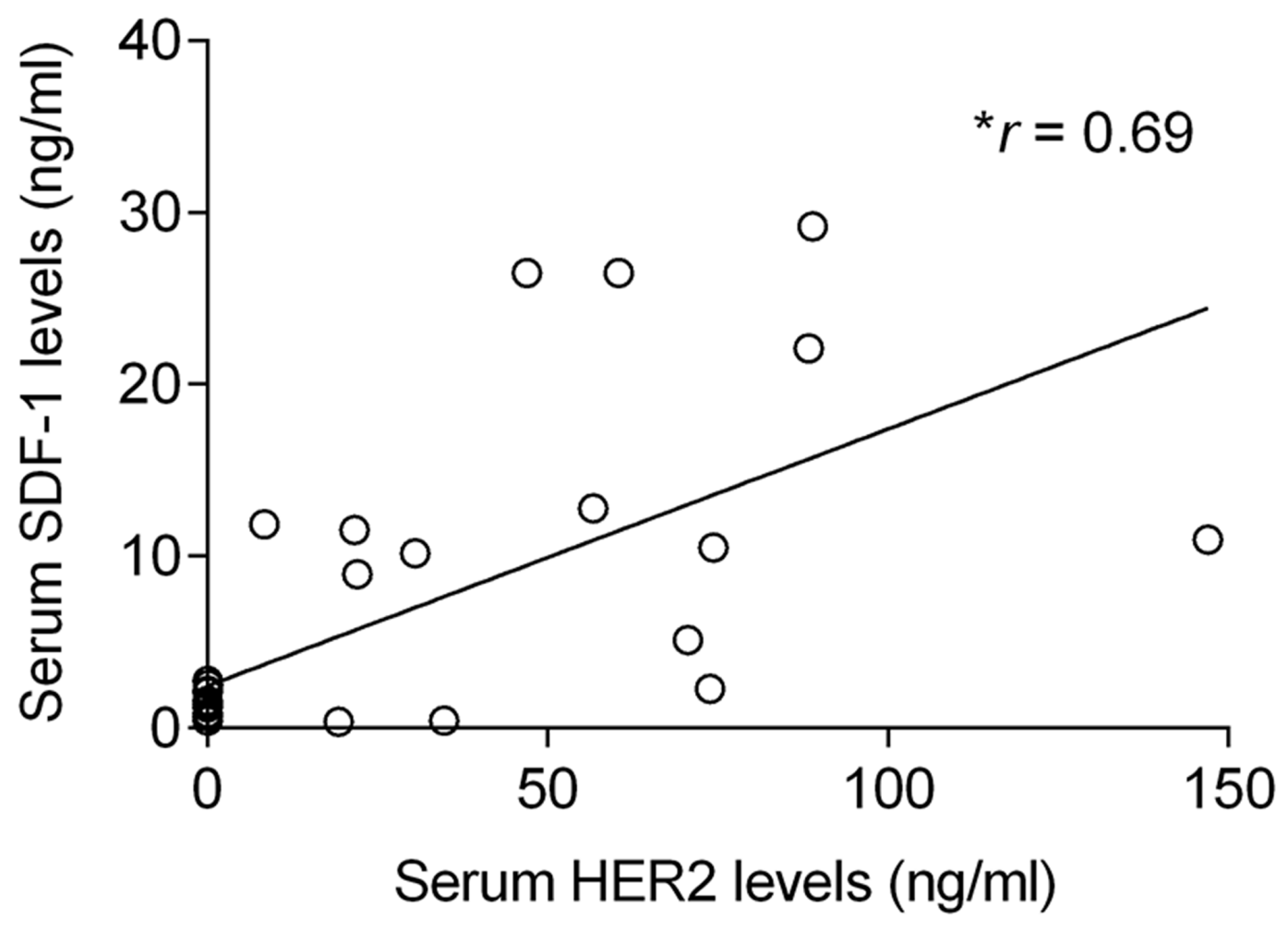

Figure 6: Elevated serum SDF-1 levels are associated with high circulating HER2 levels in cats with mammary carcinoma. The non-parametric Spearman rank test was used to assess the correlation between the serum SDF-1 levels and serum HER2 levels. $r$ means the correlation coefficient value and ${ }^{*}$ indicates significant correlation between the two variables $(p<0.0001)$. 
Table 3: Associations between serum SDF-1 levels and clinical pathological features

Serum SDF-1 levels

Low $(<2 \mathrm{ng} / \mathrm{ml})$

High $(\geq 2 \mathrm{ng} / \mathrm{ml})$

$p$ Values and odd ratios

(n)

(n)

(OR)

Size class

$\leq 3 \mathrm{~cm}$

10

$>3 \mathrm{~cm}$

7

21

1

$p=0.012$

Recurrence

No

Yes

11

6

Alive

No

Yes

Multitumors

No

Yes

Necrosis

No

Yes

5

11

Lymphatic vessel invasion

Yes

No

3

14

Lymphocytic infiltration

No

Yes

9

8

Lymph node metastasis

No

Yes

11

6

Ki-67 index

Low $(<14 \%)$

$\operatorname{High}(\geq 14 \%)$

4

13

PR status

Negative

Positive

9

8

ER status

Negative

Positive

11

6

\section{HER2 status}

Negative (scores 0 and $1+$ )

Positive (scores $2+$ and $3+$ )

implied in the inhibition of the SDF-1-induced CXCR4 ubiquitination [32]. Very recently, it was also found that
CXCR4 could be a very promising therapeutic target in patients with HER2-overexpressing breast cancer patients, 
since CXCR4 inhibitors efficiently reduced tumor growth and metastasis in both Herceptin-sensitive and Herceptinresistant HER2 patient-derived xenografts [33]. Further studies on SDF-1 and CXCR4 gene expression in primary and metastatic HER-2 tumors are in need to be performed in order to gain a better knowledge on how SDF-1/ CXCR4 axis is acting at the molecular level in woman and female cat.
In summary, our work identified a new serum biomarker for feline mammary carcinoma, in particular for HER2-tumors, opening new perspectives for the development of diagnostic tools and design of new therapies targeting the SDF-1/CXCR4 axis. Further, the results also reinforce the scenario that $\mathrm{FMC}$ is a suitable spontaneous cancer model which may allow to predict novel therapeutic strategies in humans.

\section{A}
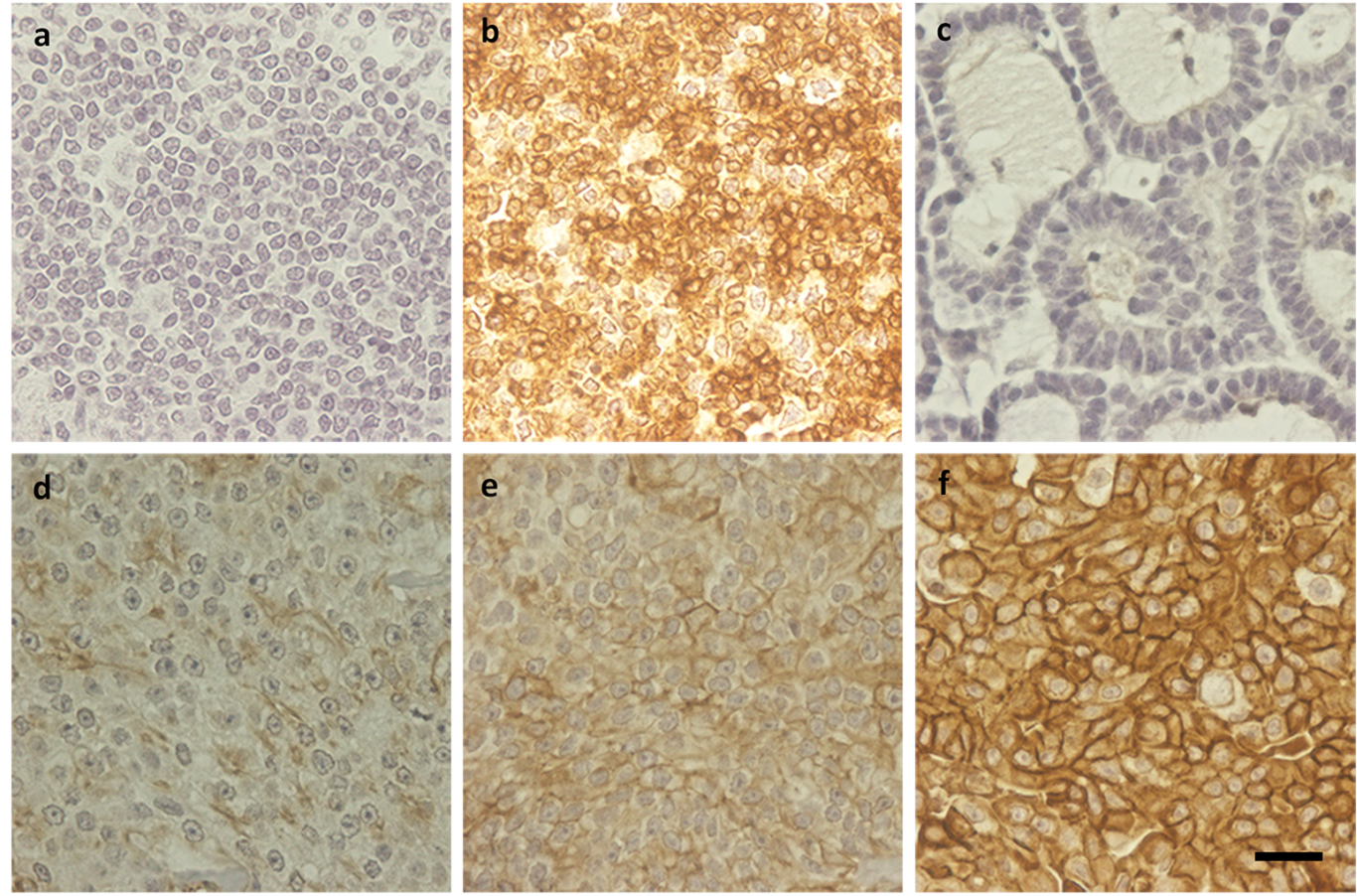

B

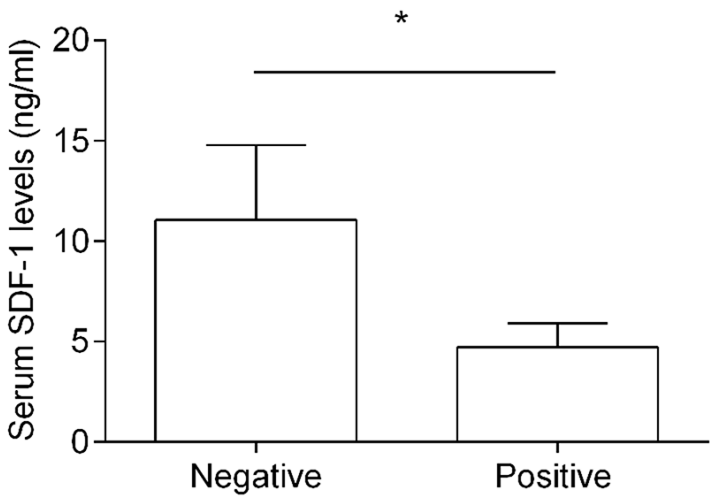

Tissue CXCR4 status

Figure 7: Cats with CXCR4-positive mammary carcinoma show low serum SDF-1 levels. (A) The CXCR4 expression was assessed by immunohistochemistry using normal feline lymphoid tissue (tonsil) as negative (a) and positive controls (b). Healthy mammary tissue scored as 0 (c) and samples of mammary carcinomas scored as $1+, 2+$ and $3+(\mathrm{d}-\mathrm{f})$ are presented. The total magnification is $400 \mathrm{x}$ and the scale bar represents $20 \mu \mathrm{m}$. (B) The non-parametric Mann-Whitney was used to compare serum SDF-1 levels between the cats having CXCR4-negative mammary carcinoma and cats with CXCR4-overexpressing mammary carcinoma. Bars represent the mean value \pm SEM and ${ }^{*}$ indicates a significant difference $(p=0.027)$. 


\section{MATERIALS AND METHODS}

\section{Sample collection}

Forty-two blood samples from cats with spontaneous mammary carcinomas and 10 from healthy cats, that underwent surgical treatment at the Small Animal Hospital of the Veterinary Medicine Faculty, University of Lisbon (FVM-ULisboa), were selected in a prospective study from June 2012 to December 2016, after the owner's cat permission.

For each animal, the following clinicopathological features were recorded: age, breed, reproductive status, progestogens administration, prescribed treatment (none, surgery, surgery plus chemotherapy), number and location of tumor lesions, tumor size, lymph node status, histopathological classification, malignancy grade, presence of tumor necrosis, lymphatic vessel invasion by tumor cells, lymphocytic infiltration, cutaneous ulceration, regional lymph node involvement, stage of the disease (TNM system) [61], disease-free survival (DFS) and overall survival (OS) were recorded.

Serum was separated from clotted blood by centrifugation $\left(1500 \mathrm{~g}, 10 \mathrm{~min}, 4^{\circ} \mathrm{C}\right)$ and immediately frozen at $-80^{\circ} \mathrm{C}$, until use. All samples that showed hemolysis were discarded, as recommended for humans [62]. Excised mammary glands, mammary tumors and regional lymph nodes from the animals were immediately fixed in $10 \%$ formalin neutralized with $0.1 \mathrm{M}$ phosphate buffer ( $\mathrm{pH} 7.2$ ), during a period no longer than 48 hours. All samples were embedded into paraffin blocks and serial histological sections of $3 \mu \mathrm{m}$ thickness were prepared, prior to hematoxylin and eosin staining. Carcinomas are classified according to the WHO system adapted by Misdorp et al., 1999 [63] and the degree of malignancy was assessed according to the Elston and Ellis grading system [64], which classifies tumors into grade I (well differentiated), grade II (moderately differentiated), and grade III (poorly differentiated).

\section{Tissue HER2, ER, PR, Ki-67 and CXCR4 status assessment by IHC}

A representative area of each FMC with a diameter of $0.6 \mathrm{~cm}$ was selected and tissue sections of $3 \mu \mathrm{m}$ thickness were mounted on glass slides (Star Frost adhesive glass slides, Thermo Scientific, Rockford, USA), placed for $1 \mathrm{~h}$ at $65^{\circ} \mathrm{C}$ and overnight at $37^{\circ} \mathrm{C}$ to properly bind the tissue to the glass. Then tissue samples were deparaffinized with xylene and rehydrated through graded alcohols series to distilled water. For HER2, ER and Ki67 immunostaining, antigen retrieval was performed by immersing glass tissue slides in citrate buffer $(0.01 \mathrm{M}$ $\mathrm{NaCH} 3 \mathrm{COO}, \mathrm{pH} 6.0$ ) and using a pressure cooker (2 min at $2 \mathrm{~atm}$ ), while for PR immunodetection, an immersion in water bath $\left(60 \mathrm{~min}\right.$ at $\left.95^{\circ} \mathrm{C}\right)$ was performed, as previous reported in [7] and references therein. For CXCR4 detection, tissue slides were immersed in Novocastra ${ }^{\mathrm{TM}}$ epitope retrieval solution $\mathrm{pH} 9$ (Leica Biosystems, Wetzlar, Germany) and boiled (25 min at $600 \mathrm{~W}$ ) in a microwave for heat induced epitope retrieval. Then slides were cooled for $30 \mathrm{~min}$ at room temperature and rinsed twice for $5 \mathrm{~min}$ in PBS. Afterwards, the endogenous peroxidase activity was inhibited by an incubation with hydrogen peroxide $(3-4 \% \mathrm{v} / \mathrm{v})$ during $15 \mathrm{~min}$ followed by a protein block $(0.4 \%$ casein in PBS, with stabilizers, surfactant, and $0.2 \%$ Bronidox) for $10 \mathrm{~min}$.

Tissue samples were then incubated at $4^{\circ} \mathrm{C}$ overnight, in a humidified chamber, with the following primary antibodies: mouse anti-HER2 (clone CB11, 1:200, Invitrogen, Carlsbad, CA, USA), mouse antiER (clone 6F11, 1:125, Thermo Scientific), rabbit antiPR (clone 1E2, ready-to-use, Ventana, Tucson, USA), rabbit anti-Ki-67 (polyclonal, 1:500, Thermo Scientific) and rabbit monoclonal anti-CXCR4 antibody (clone UMB2, Abcam, Cambridge, UK), diluted 1:500 in Lab Vision ${ }^{\mathrm{TM}}$ Antibody Diluent OP Quanto (Thermo Fisher Scientific Inc., Waltham, USA). The staining was performed using a modified streptavidin-peroxidase conjugate method based on the poly-HRP anti-rabbit IgG detection system (Novolink ${ }^{\mathrm{TM}}$ Polymer Detection System, Leica Biosystems, Wetzlar, Germany), following the manufacturer's guidelines. The peroxidase activity was developed with DAB chromogen $(1.74 \%$ w/v 3,3 diaminobenzidine) in Novolink ${ }^{\mathrm{TM}}$ DAB Substrate Buffer (buffered solution containing $\leq 0.1 \%$ hydrogen peroxide and preservative) for $5 \mathrm{~min}$.. Finally, tissue sections were counterstained for 2 min with Mayer's hematoxylin (Merck, New Jersey, USA), dehydrated and mounted with Entellan ${ }^{\circledR}$ mounting medium (Merck Millipore, Darmstadt, Germany). HER2 immunoreactivity was scored according to the American Society of Clinical Oncology's recommendations. Briefly, FMC were classified as HER2-negative when scored 0 or +1 and HER2-positive if scored as +2 or +3 . Mammary carcinomas were also evaluated for ER/PR status using the Allred score system, and only tumors with a score $\geq 2$ were considered positive. The Ki-67 proliferation index was determined by dividing the number of tumoral cells showing positive nuclear immunostaining per 1000 tumor cells analyzed over at least three high-amplified microscopic fields. Tumors were considered highly proliferative when more than $14 \%$ of the neoplastic cells nuclei expressed $\mathrm{Ki}-67$, as previously reported.

The scoring system for CXCR4 was adopted from previous studies in humans and cats $[19,21,26,46]$. The intensity of cell membrane and/or cytoplasm staining was graded as 0 (negative), 1 (weak), 2 (moderate) and 3 (strong). The percentage of staining cells obtained, evaluating at least 1000 neoplastic cells in 10 high-power fields (400× magnification) for each tissue section, was also classified as $0=$ negative, $1=<10 \%, 2=10-50 \%$, 
and $3=>50 \%$. Multiplication of intensity and percentage scores were used to determine the staining index $(0,1$, $2,3,4,6$, and 9) and the final results were categorized as reported: staining indexes 0 and 1 were considered CXCR4-negative (0), as the staining indexes 2 and 3 $(1+)$, while the staining indexes 4 and 6 were considered positive $(2+)$ as the staining index $9(3+)$.

Samples of feline mammary carcinomas with previous known ER/PR/HER2 status were used as controls, whereas a feline tonsil tissue sample was used as a positive control for the assessment of $\mathrm{Ki}-67$ index and CXCR4, according to the manufacturer's instructions. Tissue sections without incubation of primary antibodies were used as negative controls.

All slides were independently subjected to blind scoring by two independent pathologists and discordant interpretations were further debated and settled using a multiobserver microscope. Images were taken with a color optical microscope system (Axiovert S100 with AxioCam HRc; Carl Zeiss BV, Sliedrecht, the Netherlands) and analyzed using AxioVision (Carl Zeiss).

\section{Quantification of serum SDF-1 and HER2 levels by ELISA}

Considering the extensive sequence homology between the human SDF-1 ligand and human HER2 receptor with theirs homologues in Felis catus (96\% and 93\%, respectively), serum SDF-1 and HER2 levels were evaluated by using two commercial ELISA-based kits suitable to use in humans (CXCL12/SDF-1 DuoSet ELISA kit, R\&D Systems, Minneapolis, USA; sHER2 Platinum ELISA kit, eBioscience, San Diego, USA), following the manufacturer's protocol. Briefly, for each ELISA assay, a standard curve was generated using seven dilutions of the recombinant SDF-1 or HER2 protein, with known concentrations. Then, the first row of a 96-well ELISA plate was coated with $100 \mu \mathrm{l} /$ well of each rSDF-1 or rHER2-ECD dilution, in duplicate, on "standards wells", whereas $10 \mu \mathrm{l}$ of each serum sample was added to $90 \mu \mathrm{l}$ of assay buffer in "sample wells", also in duplicates. After two consecutive washes $(2 \times 300 \mu$ l with Wash Buffer $)$, $50 \mu \mathrm{l}$ of an HRP-conjugated mouse anti-IgG was added to each well and incubated at $37^{\circ} \mathrm{C}$, for 2 hours, on a microplate shaker at $100 \mathrm{rpm}$. After a second washing step $(3 \times 300 \mu \mathrm{l}), 100 \mu \mathrm{l}$ of the 3,3',5,5'-tetramethyl-benzidine (TMB) substrate solution was added to each well and the final mixture was incubated at RT, for $10 \mathrm{~min}$, in the dark.

For quantification of serum SDF-1 levels, a 96well ELISA plate was coated overnight with $1 \mu \mathrm{g} / \mathrm{ml}$ of mouse anti-human SDF-1 capture antibody (100 $\mu \mathrm{l})$ in 1\% bovine serum albumin (BSA) - phosphate buffer solution (PBS). After several washes (0.05\% Tween-20 in PBS), each well was blocked (1\% BSA PBS) for $1 \mathrm{~h}$ to prevent non-specific binding and $100 \mu \mathrm{l}$ of diluted serum samples (1:10) and standards were incubated for $2 \mathrm{~h}$. The plate was washed and $50 \mathrm{ng} / \mathrm{ml}$ of the biotinylated goat anti-human SDF-1 detection antibody (100 $\mu$ l) was added to each well for $1 \mathrm{~h}$ incubation. Conjugated streptavidin-horseradish peroxidase (HRP) was diluted 40 times and incubated in the plate wells for $45 \mathrm{~min}$ after previous washes. A final wash was performed before adding 100ul of the HRP substrate $\left(3,3^{\prime}, 5,5^{\prime}\right.$-tetramethylbenzidine) solution (R\&D Systems, Minneapolis, USA). After $25 \mathrm{~min}$ of incubation in the dark, the reaction was stopped with 50 $\mu \mathrm{l}$ of $2 \mathrm{~N}$ sulfuric acid and the absorbance was measured in a spectrophotometer (LabSystems IEMS Reader MF, Labsystems/Thermo Scientific, Helsinki, Finland) using $450 \mathrm{~nm}$ as the primary wavelength and $570 \mathrm{~nm}$ as reference wavelength. Quantification of serum HER2 levels was performed as previously reported by us [7].

\section{Statistical analysis}

Graphpad Prism version 7.02 (La Jolla, USA) was used for all statistical analysis and a two-tailed $p$ value less than 0.05 was considered statistically significant. Outliers were removed from analysis based on the combination of Robust regression and Outlier removal, ROUT method [65] implemented in Graphpad Prism software. This method identifies outliers from nonlinear curve fits with reasonable power and few false positives [65]. The nonparametric Mann-Whitney test was used to compare the serum SDF-1 levels between healthy cats and cats with mammary carcinoma, and cats with CXCR4-negative and CXCR4-positive mammary carcinomas. Receiver-operating characteristics (ROC) curves were performed to choose the best cut-off value for serum SDF-1 levels using ELISA and to determine the sensitivity and specificity of the assay. The non-parametric Kruskall-Wallis test and the Dunn's multiple comparisons post-test were used to compare serum SDF1 levels in healthy cats and cats with different mammary carcinoma subtypes. The Fisher's exact test was used to assess the associations between serum SDF-1 levels and clinicopathological features (categorical variables, placed in ordinal or nominal scale). The correlation coeficient of Pearson was calculated to correlate the serum SDF-1 levels with the clinicopathological features measured in a metric scale (continuous variables).

OS and DFS were analyzed by the Kaplan-Meier method (log-rank test). Overall survival (OS) period was defined as the time elapsed between the initial diagnosis and the death/euthanasia due to tumor metastasis. Diseasefree survival (DFS) time was calculated from the date of surgery to the date of relapse (local, in other mammary gland or in distant organs) or death from cancer-related causes. Survival curves were estimated using the KaplanMeier method and the Log-rank test to compare the outcome (OS median and DFS median), regarding serum SDF-1 levels. Finally, animals that died from a disease unrelated to mammary tumors or were lost during the follow-up were excluded for the OS analysis. 


\section{Abbreviations}

AUC: area under the curve, BSA: bovine serum albumin, CI: confidence interval, CXCL12: chemokine ligand 12, CXCR4: C-X-C Chemokine Receptor Type 4, CXCR7: C-X-C Chemokine Receptor Type 7, DFS: disease free-survival, ELISA: enzyme-linked immunosorbent assay, ER: estrogen receptor, ERK1/2: extracellular signal-regulated kinase 1/2, FMC: feline mammary carcinoma, GPCR: chemokine receptors G protein-coupled receptors, HER2: human epidermal growth factor receptor type II, HIF-1 $\alpha$ : hypoxia inducible factor 1 alpha, HRP: horseradish peroxidase, IFN- $\gamma$ : interferon-gamma, LA: Luminal A, LB: Luminal B, MAPK: mitogen-activated protein kinase, NF- $\mathrm{kB}$ : nuclear factor kappa light-chain-enhancer of activated B cells, OR: odd ratio, OS: overall survival, PBS: phosphate buffer solution, PI3K: phosphoinositide 3-kinase, PR: progesterone receptor, $r$ : Spearman correlation coefficient, ROC: receiver-operating characteristics, SDF-1: stromal cell-derived-factor-1, SEM: standard error of mean, sHER2: serum HER2, , TBS: tris-buffered saline, TGF- $\beta 1$ : transforming growth factor-beta $1, \mathrm{TN}$ : triple negative, VEGF: vascular endothelial growth factor.

\section{Author contributions}

Conceived and designed the experiments: CSM, FF. Performed the experiments: CSM, MJS. Analyzed the data: CSM, MJS, AS, JC and FF. Wrote and reviewed the paper: CSM, MJ, AS and FF.

\section{ACKNOWLEDGMENTS}

The authors would like to thank Dr. Sandra Carvalho from the Veterinary Pathology Diagnostic Services at Faculty of Veterinary Medicine, for her kind assistance in the immunohistochemistry assay; to Prof. António Ferreira (DVM, PhD), Dr. Ana Murta (DVM, MSc) and Dr. Rodrigo Bom (DVM) from the Small Animal Hospital, of the Faculty of Veterinary Medicine, University of Lisbon; to Dr. Manuel Mestre (DVM), Dr. Ana Mota (DVM, MSc) and Dr. Tiago Rafael (DVM, MSc) from Clínica Veterinária Zoomédica; to Dr. Mafalda Lage (DVM, MSc) from Clínica Veterinária Villa Animal; to Dr. Rafaela Lalanda (DVM, MSc) and Dr. Miguel Caninhas (DVM) from Clínica Veterinária Mvet; and to Dr. Verónica Azevedo (DVM, MSc) from Hospital Sul do Tejo for the clinical follow-up.

\section{CONFLICTS OF INTEREST}

The authors declared no potential conflicts of interest regarding the research, authorship and/or publication of this article.

\section{FUNDING}

This research was supported by Fundação para a Ciência e Tecnologia through the projects PTDC/CVTEPI/3638/2014 and CIISA-UID/CVT/00276/2013.

\section{REFERENCES}

1. Vascellari M, Baioni E, Ru G, Carminato A, Mutinelli F. Animal tumour registry of two provinces in northern Italy: incidence of spontaneous tumours in dogs and cats. BMC Vet Res. 2009; 5: 39. https://doi. org/10.1186/1746-6148-5-39.

2. Ordás J, Millán Y, Dios R, Reymundo C, de las Mulas J. Proto-oncogene HER-2 in normal, dysplastic and tumorous feline mammary glands: an immunohistochemical and chromogenic in situ hybridization study. BMC Cancer. 2007; 7: 1471-2407. https://doi.org/10.1186/1471-2407-7-179.

3. Soares M, Correia J, Rodrigues P, Simões M, de Matos A, Ferreira F. Feline HER2 protein expression levels and gene status in feline mammary carcinoma: optimization of immunohistochemistry (IHC) and in situ hybridization (ISH) techniques. Microsc Microanal. 2013; 19: 876-882. https://doi.org/10.1017/S1431927613001529.

4. Millanta F, Calandrella M, Citi S, Della Santa D, Poli A. Overexpression of HER-2 in feline invasive mammary carcinomas: an immunohistochemical survey and evaluation of its prognostic potential. Vet Pathol. 2005; 42: 30-34. https://doi.org/10.1354/vp.42-1-30.

5. Maniscalco L, Iussich S, Martín de las Mulas J, Millán Y, Biolatti B, Sasaki N, Nakagawa T, De Maria R. Activation of AKT in feline mammary carcinoma: a new prognostic factor for feline mammary tumours. Vet J. 2012; 191: 65-71. https://doi.org/10.1016/j.tvj1.2010.12.016.

6. Hassan BB, Elshafae SM, Supsavhad W, Simmons JK, Dirksen WP, Sokkar SM, Rosol TJ. Feline mammary cancer. Vet Pathol. 2017; 54: 32-43. https://doi. org/10.1177/0300985816650243.

7. Soares M, Madeira S, Correia J, Peleteiro M, Cardoso F, Ferreira F. Molecular based subtyping of feline mammary carcinomas and clinicopathological characterization. Breast. 2016; 27: 44-51. https://doi.org/10.1016/j. breast.2016.02.016.

8. Marques C, Correia J, Ferreira F. HER2-positive feline mammary carcinoma. Aging (Albany NY). 2016; 8: 15741575. https://doi.org/10.18632/aging.101015.

9. Zappulli V, Rasotto R, Caliari D, Mainenti M, Peña L, Goldschmidt MH, Kiupel M. Prognostic evaluation of feline mammary carcinomas. Vet Pathol. 2014; 52: 46-60. https://doi.org/10.1177/0300985814528221.

10. Adega F, Borges A, Chaves R. Cat mammary tumors: genetic models for the human counterpart. Vet Sci. 2016; 3: 17. https://doi.org/10.3390/vetsci3030017. 
11. Soares M, Ribeiro R, Najmudin S, Gameiro A, Rodrigues $\mathrm{R}$, Cardoso F, Ferreira F. Serum HER2 levels are increased in cats with mammary carcinomas and predict tissue HER2 status. Oncotarget. 2016; 7: 17314-17326. https://doi. org/10.18632/oncotarget.7551.

12. Cardoso F, Harbeck N, Barrios CH, Bergh J, Cortés J, El Saghir N, Francis PA, Hudis CA, Ohno S, Partridge AH, Sledge GW, Smith IE, Gelmon KA. Research needs in breast cancer. Ann Oncol. 2017; 28: 208-217. https://doi. org/10.1093/annonc/mdw571.

13. Chow MT, Luster AD. Chemokines in cancer. Cancer Immunol Res. 2014; 2: 1125-1131. https://doi. org/10.1158/2326-6066.CIR-14-0160.

14. Palacios-Arreola MI, Nava-Castro KE, Castro JI, GarcíaZepeda E, Carrero JC, Morales-Montor J. The role of chemokines in breast cancer pathology and its possible use as therapeutic targets. J Immunol Res. 2014. https://doi. org/10.1155/2014/849720.

15. Sun X, Cheng G, Hao M, Zheng J, Zhou X, Zhang J, Taichman RS, Pienta KJ, Wang J. CXCL12 / CXCR4 / CXCR7 chemokine axis and cancer progression. Cancer Metastasis Rev. 2010; 29: 709-722. https://doi.org/10.1007/ s10555-010-9256-x.

16. Zhao H, Guo L, Zhao H, Zhao J, Weng H, Zhao B, Zhao H, Guo L, Zhao H, Zhao J, Weng H, Zhao B. CXCR4 overexpression and survival in cancer: a system review and meta-analysis. Oncotarget. 2015; 6: 5022-5040. https://doi. org/10.18632/oncotarget.3217.

17. Domanska UM, Kruizinga RC, Nagengast WB, TimmerBosscha H, Huls G, de Vries EG, Walenkamp AM. A review on CXCR4/CXCL12 axis in oncology: no place to hide. Eur J Cancer. 2013; 49: 219-230. https://doi.org/10.1016/j. ejca.2012.05.005.

18. Luker KE, Luker GD. Functions of CXCL12 and CXCR4 in breast cancer. Cancer Lett. 2006; 238: 30-41. https://doi. org/10.1016/j.canlet.2005.06.021.

19. Hassan S, Ferrario C, Saragovi U, Quenneville L, Gaboury L, Baccarelli A, Salvucci O, Basik M. The influence of tumor-host interactions in the stromal cell-derived factor-1/ CXCR4 ligand/receptor axis in determining metastatic risk in breast cancer. Am J Pathol. 2009; 175: 66-73. https://doi. org/10.2353/ajpath.2009.080948.

20. Luker KE, Lewin SA, Mihalko LA, Schmidt BT, Winkler JS, Coggins NL, Thomas DG, Luker GD. Scavenging of CXCL1 2 by CXCR7 promotes tumor growth and metastasis of CXCR4-positive breast cancer cells. Oncogene. 2012; 31: 4750-4758. https://doi.org/10.1038/onc.2011.633.

21. Sun Y, Mao X, Fan C, Liu C, Guo A, Guan S, Jin Q, Li B, Yao F, Jin F. CXCL12-CXCR4 axis promotes the natural selection of breast cancer cell metastasis. Tumor Biol. 2014; 35: 7765-7773. https://doi.org/10.1007/s13277-014-1816-1.

22. Xu C, Zhao H, Chen H, Yao Q. CXCR4 in breast cancer: oncogenic role and therapeutic targeting. Drug Des Devel
Ther. 2015; 9: 4953-4964. https://doi.org/10.2147/DDDT. S84932.

23. Mego M, Cholujova D, Minarik G, Sedlackova T, Gronesova P, Karaba M, Benca J, Cingelova S, Cierna Z, Manasova D, Pindak D, Sufliarsky J, Cristofanilli M, et al. CXCR4-SDF-1 interaction potentially mediates trafficking of circulating tumor cells in primary breast cancer. BMC Cancer. 2016; 16: 127. https://doi.org/10.1186/ s12885-016-2143-2.

24. Muller A, Homey B, Soto H, Ge N, Catron D, Buchanan ME, McClanahan T, Murphy E, Yuan W, Wagner SN. Involvement of chemokine receptors in breast cancer metastasis. Nature. 2001; 410: 50-56. https://doi. org/10.1038/35065016.

25. Salvucci O, Bouchard A, Baccarelli A, Deschenes J, Sauter G, Simon R, Bianchi R, Basik M. The role of CXCR4 receptor expression in breast cancer: a large tissuemicroarray study. Breast Cancer Res Treat. 2006; 97: 275-283. https://doi.org/10.1007/s10549-005-9121-8.

26. Papatheodorou H, Papanastasiou AD, Sirinian C, Scopa C, Kalofonos HP, Leotsinidis M, Papadaki H. Expression patterns of SDF1/CXCR4 in human invasive breast carcinoma and adjacent normal stroma: correlation with tumor clinicopathological parameters and patient survival. Pathol Res Pract. 2014; 210: 662-667. https://doi. org/10.1016/j.prp.2014.06.015.

27. Xu T, Shen H, Liu L, Shu Y. The impact of chemokine receptor CXCR4 on breast cancer prognosis: a metaanalysis. Cancer Epidemiol. 2013; 37: 725-731. https://doi. org/10.1016/j.canep.2013.04.017.

28. Zhang Z, Ni C, Chen W, Wu P, Wang Z, Yin J, Huang J, Qiu F. Expression of CXCR4 and breast cancer prognosis: a systematic review and meta-analysis. BMC Cancer. 2014; 14: 49. https://doi.org/10.1186/1471-2407-14-49.

29. Zhang M, Liu H, Teng X, Wang H, Cui J, Jia S, Gu X, Li Z. The differences in CXCR4 protein expression are significant for the five molecular subtypes of breast cancer. Ultrastruct Pathol. 2012; 36: 381-386. https://doi.org/10.31 09/01913123.2012.728687.

30. Sivrikoz ON, Doganay L, Sivrikoz UK, Karaarslan S, Sanal SM. Distribution of CXCR4 and $\gamma$-catenin expression pattern in breast cancer subtypes and their relationship to axillary nodal involvement. Pol J Pathol. 2013; 64: 253259. https://doi.org/10.5114/pjp.2013.39333.

31. Strien L, Joensuu K, Heikkila P, Leidenius M. Different expression patterns of CXCR4, CCR7, maspin and FOXP3 in luminal breast cancers and their sentinel node metastases. Anticancer Res. 2017; 37: 175-182. https://doi. org/10.21873/anticanres.11303.

32. Li YM, Pan Y, Wei Y, Cheng X, Zhou BP, Tan M, Zhou X, Xia W, Hortobagyi GN, Yu D. Upregulation of CXCR4 is essential for HER2-mediated tumor metastasis. Cancer Cell. 2004; 6: 459-469. https://doi.org/10.1016/j.ccr.2004.09.027. 
33. Lefort S, Thuleau A, Kieffer Y, Sirven P, Bieche I, Marangoni E, Vincent-Salomon A, Mechta-Grigoriou F. CXCR4 inhibitors could benefit to HER2 but not to triplenegative breast cancer patients. Oncogene. 2017; 36: 12111222. https://doi.org/10.1038/onc.2016.284.

34. Chu QD, Panu L, Holm NT, Li BD, Johnson LW, Zhang S. High chemokine receptor CXCR4 level in triple negative breast cancer specimens predicts poor clinical outcome. J Surg Res. 2010; 159: 689-695. https://doi.org/10.1016/j. jss.2008.09.020.

35. Chen HW, Du CW, Wei XL, Khoo US, Zhang GJ. Cytoplasmic CXCR4 high-expression exhibits distinct poor clinicopathological characteristics and predicts poor prognosis in triple-negative breast cancer. Curr Mol Med. 2013; 13: 410 416. https://doi.org/10.2174/1566524011313030010.

36. Yu S, Wang X, Liu G, Zhu X, Chen Y. Highlevel of CXCR4 in triple-negative breast cancer specimens associated with a poor clinical outcome. Acta Med Okayama. 2013; 67: 369-375. https://doi.org/NAO TEM DOI.

37. Li RH, Huang WH, Wu JD, Du CW, Zhang GJ. EGFR expression is associated with cytoplasmic staining of CXCR4 and predicts poor prognosis in triple-negative breast carcinomas. Oncol Lett. 2017; 13: 695-703. https:// doi.org/10.3892/ol.2016.5489.

38. Dunn LK, Mohammad KS, Fournier PG, McKenna CR, Davis HW, Niewolna M, Peng XH, Chirgwin JM, Guise TA. Hypoxia and TGF- $\beta$ drive breast cancer bone metastases through parallel signaling pathways in tumor cells and the bone microenvironment. PLoS One. 2009; 4: e6896. https:// doi.org/10.1371/journal.pone.0006896.

39. Lopez-Haber C, Barrio-Real L, Casado-Medrano V, Kazanietz MG. Heregulin/ErbB3 signaling enhances CXCR4-driven Rac1 activation and breast cancer cell motility via hypoxia-inducible factor $1 \alpha$. Mol Cell Biol. 2016; 36: 2011-2026. https://doi.org/10.1128/ MCB.00180-16.

40. Hassan S, Baccarelli A, Salvucci O, Basik M. Plasma stromal cell-derived factor-1: host derived marker predictive of distant metastasis in breast cancer. Clin Cancer Res. 2008; 14: 446-454. https://doi.org/10.1158/1078-0432. CCR-07-1189.

41. Orimo A, Gupta PB, Sgroi DC, Arenzana-Seisdedos F, Delaunay T, Naeem R, Carey VJ, Richardson AL, Weinberg RA. Stromal fibroblasts present in invasive human breast carcinomas promote tumor growth and angiogenesis through elevated SDF-1/CXCL12 secretion. Cell. 2005; 121: 335-348. https://doi.org/10.1016/j.cell.2005.02.034.

42. Kang H, Watkins G, Parr C, Douglas-Jones A, Mansel RE, Jiang WG. Stromal cell derived factor-1: its influence on invasiveness and migration of breast cancer cells in vitro, and its association with prognosis and survival in human breast cancer. Breast Cancer Res. 2005; 7: 402-410. https:// doi.org/10.1186/bcr1022.

43. Potter SM, Dwyer RM, Curran CE, Hennessy E, Harrington KA, Griffin DG, Kerin MJ. Systemic chemokine levels in breast cancer patients and their relationship with circulating menstrual hormones. Breast Cancer Res Treat. 2009; 115: 279-287. https://doi.org/10.1007/s10549-008-0078-2.

44. Kang W, Watkins G, Douglas-Jones A, Mansel RE, Jiang WG. The elevated level of CXCR4 expression is correlated with lymph node metastasis in human breast cancer. Breast. 2005; 14: 360-367. https://doi.org/10.1016/j. breast.2004.12.007.

45. Tanabe S, Nakadai T, Furuoka H, Oomachi T, Kobayashi Y, Omata Y, Koyama T, Hondo E, Uzuka Y, Sarashina T, Ducusin RJT, Shida T, Dorf ME. Expression of mRNA of chemokine receptor CXCR4 in feline mammary adenocarcinoma. Vet Rec. 2002; 151: 729-733. https://doi. org/10.1136/vr.154.24.729.

46. Ferrari A, Petterino C, Ratto A, Campanella C, Wurth R, Thellung S, Vito G, Barbieri F, Florio T. CXCR4 expression in feline mammary carcinoma cells: evidence of a proliferative role for the SDF-1/CXCR4 axis. BMC Vet Res. 2012; 8: 27. https://doi.org/10.1186/1746-6148-8-27.

47. Mirisola V, Zuccarino A, Bachmeier BE, Sormani MP, Falter J, Nerlich A, Pfeffer U. CXCL12/SDF1 expression by breast cancers is an independent prognostic marker of disease-free and overall survival. Eur J Cancer. 2009; 45: 2579-2587. https://doi.org/10.1016/j.ejca.2009.06.026.

48. Zlotnik A, Burkhardt AM, Homey B. Homeostatic chemokine receptors and organ-specific metastasis. Nat Rev Immunol. 2011; 11: 597-606. https://doi.org/10.1038/nri3049.

49. Gil M, Seshadri M, Komorowski MP, Abrams SI, Kozbor D. Targeting CXCL12/CXCR4 signaling with oncolytic virotherapy disrupts tumor vasculature and inhibits breast cancer metastases. Proc Natl Acad Sci U S A. 2013; 110: 1291-1300. https://doi.org/10.1073/pnas.1220580110.

50. Katkoori VR, Basson MD, Bond VC, Manne U, Bumpers HL. Nef-M1, a peptide antagonist of CXCR4, inhibits tumor angiogenesis and epithelial-to-mesenchymal transition in colon and breast cancers. Oncotarget. 2015; 6: 27763-27777. https://doi.org/10.18632/oncotarget.4615.

51. Wang Y, Xie Y, Oupický D. Potential of CXCR4/ CXCL12 chemokine axis in cancer drug delivery. Curr Pharmacol Rep. 2016; 2: 1-10. https://doi.org/10.1007/ s40495-015-0044-8.

52. Azad BB, Chatterjee S, Lesniak WG, Lisok A, Pullambhatla M, Bhujwalla ZM, Pomper MG, Nimmagadda S. A fully human CXCR4 antibody demonstrates diagnostic utility and therapeutic efficacy in solid tumor xenografts. Oncotarget. 2016; 7: 12344-12358. https://doi.org/10.18632/ oncotarget. 7111.

53. Jiang K, Li J, Yin J, Ma Q, Yan B, Zhang X, Wang L, Wang L, Liu T, Zhang Y, Fan Q, Yang A, Qiu X, et al. Targeted delivery of CXCR4-siRNA by scFv for HER2+ breast cancer therapy. Biomaterials. 2015; 59: 77-87. https://doi. org/10.1016/j.biomaterials.2015.04.030.

54. Zannettino AC, Farrugia AN, Kortesidis A, Manavis J, To LB, Martin SK, Diamond P, Tamamura H, Lapidot T, 
Fujii N, Gronthos S. Elevated serum levels of stromalderived factor- $1 \alpha$ are associated with increased osteoclast activity and osteolytic bone disease in multiple myeloma patients. Cancer Res. 2005; 65: 1700-1709. https://doi. org/10.1158/0008-5472.

55. Wang T, Zhou J, Zhang S, Bian L, Hu H, Xu C, Hao X, Liu B, Ye Q, Liu Y, Jiang Z. Meaningful interpretation of serum HER2 ECD levels requires clear patient clinical background, and serves several functions in the efficient management of breast cancer patients. Clin Chim Acta. 2016; 458: 23-29. https://doi.org/10.1016/j. cca.2016.04.025.

56. Lee MH, Jung SY, Kang SH, Song EJ, Park IH, Kong SY, Kwon YM, Lee KS, Kang HS, Lee ES. The significance of serum HER2 levels at diagnosis on intrinsic subtypespecific outcome of operable breast cancer patients. PLoS One. 2016; 11: e0163370. https://doi.org/10.1371/journal. pone. 0163370 .

57. Duffy MJ, Harbeck N, Nap M, Molina R, Nicolini A, Senkus E, Cardoso F. Clinical use of biomarkers in breast cancer: updated guidelines from the European Group on Tumor Markers (EGTM). Eur J Cancer. 2017; 75: 284-298. https://doi.org/10.1016/j.ejca.2017.01.017.

58. Lv Q, Meng Z, Yu Y, Jiang F, Guan D, Liang C, Zhou J, Lu A, Zhang G. Molecular mechanisms and translational therapies for human epidermal receptor 2 positive breast cancer. Int J Mol Sci. 2016; 17: 2095. https://doi. org/10.3390/ijms17122095.

59. Labidi S, Mejri N, Lagha A, Daoud N, El Benna H, Afrit $\mathrm{M}$, Boussen H. Targeted therapies in HER2-overexpressing metastatic breast cancer. Breast Care (Basel). 2016; 11: 418-422. https://doi.org/10.1159/000452194.

60. Arteaga CL, Sliwkowski MX, Osborne CK, Perez EA, Puglisi F, Gianni L. Treatment of HER2-positive breast cancer: current status and future perspectives. Nat Rev Clin Oncol. 2012; 9: 16-32. https://doi.org/10.1038/ nrclinonc.2011.177.

61. Misdorp W. Tumors of the mammary gland in tumors in domestic animals. Fourth edition (ed. DJ Meuteun). Iowa, USA. Iowa State Press; 2002. p. 575-606. https://doi. org/10.1002/9780470376928.ch12.

62. Lippi G, Avanzini P, Zobbi V, Ippolito L. Influence of mechanical hemolysis of blood on two D-dimer immunoassays. Blood Coagul Fibrinolysis. 2012; 23: 461463. https://doi.org/10.1097/MBC.0b013e3283549696.

63. Misdorp W. Histological classification of mammary tumors of the dog and the cat in International histological classification of tumors of domestic animals. Fourth edition. Washington, DC, USA. Armed Forces Institute of Pathology; 1999. p. 59.

64. Elston CW, Ellis IO. Assessment of histological grade in The Breast. Systemic pathology. Third edition. Edinburgh, UK. Churchill-Livingstone; 1998. p. 365-382.

65. Motulsky HJ, Brown RE. Detecting outliers when fitting data with nonlinear regression - a new method based on robust nonlinear regression and the false discovery rate. BMC Bioinformatics. 2006; 7: 123. https://doi. org/10.1186/1471-2105-7-123. 